\title{
Novel retrograde approach for percutaneous treatment of chronic total occlusions of the right coronary artery using ipsilateral collateral connections: a European centre experience
}

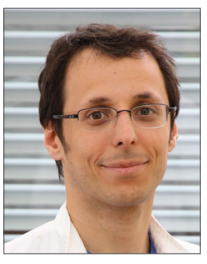

Kambis Mashayekhi ${ }^{1 *}$, MD; Michael Behnes², MD; Ibrahim Akin², MD; Thomas Kaiser ${ }^{1}$, MD; Hans Neuser ${ }^{1}$, MD

1. Internal Medicine Clinic II, Helios Vogtland Klinikum Plauen, Academic Teaching Hospital of Leipzig

University, Leipzig, Germany; 2. First Department of Medicine, University Medical Centre Mannheim (UMM),

Faculty of Medicine Mannheim, University of Heidelberg, Mannheim, Germany

K. Mashayekhi and M. Behnes contributed equally to this study.

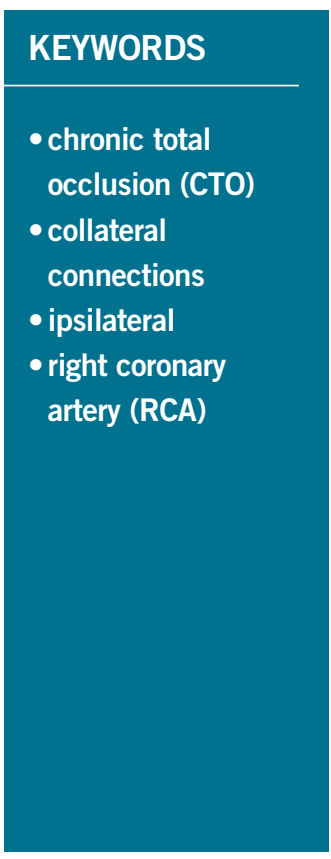

\section{Abstract}

Aims: A systematic description of the percutaneous treatment of chronic total occlusions (CTOs) of the right coronary artery (RCA) using ipsilateral collateral connections (CCs) for the retrograde approach has never been carried out. Our aim was to investigate this issue systematically.

Methods and results: Based on the experiences of a European high-volume CTO centre: 1) a generalised scheme of the varying anatomic courses of ipsilateral CCs bridging CTOs of the RCA was developed; 2) important stepwise technical advice for the ipsilateral retrograde approach was formulated; and 3) a supportive clinical case series was assessed. Of a total of 158 patients with CTOs of the RCA, $30 \%$ $(n=47)$ revealed ipsilateral CCs of the RCA. Five different types (A-E) of ipsilateral CCs were assessed. The retrograde ipsilateral approach was attempted in nine patients, and was completed successfully in $89 \%$ ( $8 / 9$ patients). Median left ventricular ejection fraction was 56\% (interquartile range [IQR]: $50-60 \%$ ) and mean J-CTO score was 2.9 (standard error of mean [SEM]: \pm 0.3 ). Median procedural duration time was $150 \mathrm{~min}$ (IQR 117-160 min), with a median applied amount of contrast of $360 \mathrm{ml}$ (IQR 270-400 ml). No relevant complications, such as acute renal failure or severe bleedings, occurred.

Conclusions: The percutaneous treatment of CTOs of the RCA using ipsilateral CCs for the retrograde approach might provide a novel treatment alternative for patients with CTOs of the RCA in specific clinical situations.

*Corresponding author: Internal Medicine Clinic II, Helios Vogtland Klinikum Plauen, Röntgenstraße 2, 08529 Plauen, Germany.E-mail: kambis.mashayekhi@helios-kliniken.de 


\section{Introduction}

Percutaneous treatment of chronic total occlusions (CTOs) of the right coronary artery (RCA) using contralateral collateral connections $(\mathrm{CCs})$ from the left coronary artery (LCA) has previously been described ${ }^{1-4}$. A few cases have described the interventional treatment of CTOs of the LCA using ipsilateral $\mathrm{CCS}^{5,6}$. However, a systematic description of the percutaneous treatment of CTOs of the RCA using right-sided ipsilateral $\mathrm{CCs}$ as the primary retrograde revascularisation approach has never been carried out in detail ${ }^{7}$. Therefore, this study aimed to investigate this issue systematically.

\section{Editorial, see page 1214}

\section{Methods}

The present analysis was performed at the Internal Medicine Clinic II of the Helios Vogtland Klinikum Plauen, Plauen, Germany, representative of a European high-volume CTO centre ${ }^{4}$. All coronary angiograms of CTOs of the RCA were evaluated by two independent cardiologists, and a generalised scheme for the varying anatomic courses of the different types of ipsilateral CCs was developed. Important stepwise technical aspects and advice for the retrograde treatment approach are presented according to the different types of ipsilateral CCs.

\section{STATISTICAL ANALYSIS}

Statistical analyses were assessed as follows. Procedural data are presented either as total numbers with percentages, or as medians with interquartile ranges (25th to 75 th percentiles) or as means \pm standard error of the mean (SEM). Fisher's exact test or the chi-square test was applied for categorical variables. For quantitative variables the Student's t-test or Mann-Whitney U test was applied depending on the distribution of the data. Statistical analyses were performed using InStat software, version 3.05 (GraphPad Software, La Jolla, CA, USA) and SPSS software, Version 22 (IBM Corp., Armonk, NY, USA). Statistical significance was declared when the two-sided p-value was $<0.05$.

\section{Results}

\section{PROCEDURAL DATA}

From January 2013 to January 2015 a total of 269 patients with CTOs were treated percutaneously at the Internal Medicine Clinic II of the Helios Vogtland Klinikum Plauen, Plauen, Germany ${ }^{4}$. The baseline characteristics of the study population are presented in Table 1. More than half of the patients (58\%) revealed a CTO of the RCA and were percutaneously treated, with a technical success rate of $94 \%$. Of these, $46 \%$ were addressed retrogradely, of whom $13 \%$ were treated using right-sided ipsilateral CCs. The success rate in these nine ipsilateral patients was $89 \%$. In one patient, the ipsilateral attempt failed and the patient had to be switched to a contralateral retrograde approach using CCs from the LCA. Detailed procedural data comparing ipsilateral with contralateral patients are presented in Table 1.

\section{ANATOMIC COURSE OF IPSILATERAL COLLATERAL CONNECTIONS OF THE RCA}

In general, ipsilateral CCs were found in $30 \%$ of patients with CTOs of the RCA. However, these patients also revealed contralateral CCs
Table 1. Baseline characteristics of patients with CTOs of the RCA being percutaneously treated using either ipsilateral or contralateral CCs.

\begin{tabular}{|l|c|c|c|}
\hline & $\begin{array}{c}\text { Ipsilateral } \\
(\mathbf{n}=9)\end{array}$ & $\begin{array}{c}\text { Contralateral } \\
(\mathbf{n}=62)\end{array}$ & $\boldsymbol{p}$-value \\
\hline Patient characteristics, median (interquartile range) \\
\hline $\begin{array}{l}\text { Age (years), median } \\
\text { (range) }\end{array}$ & $65(50-80)$ & $68(59-74)$ & 0.97 \\
\hline Male gender, n (\%) & $9(100)$ & $56(90)$ & 0.74 \\
\hline Body mass index & $29(26-31)$ & $27(25-31)$ & 0.58 \\
\hline LV ejection fraction $(\%)$ & $56(49-61)$ & $51(42-60)$ & 0.11 \\
\hline J-CTO score, mean \pm SEM & $2.9 \pm 0.3$ & $2.8 \pm 0.3$ & 0.78 \\
\hline
\end{tabular}

Technical aspects, median (interquartile range)

\begin{tabular}{|l|c|c|c|}
\hline Procedural time $(\mathrm{min})$ & $150(114-174)$ & $169(111-231)$ & 0.12 \\
\hline Fluoroscopic time $(\mathrm{min})$ & $78(62-95)$ & $83(51-121)$ & 0.30 \\
\hline $\begin{array}{l}\text { Area dose product } \\
\left(\mathrm{cGy}{ }^{*} \mathrm{~cm}^{2}\right)\end{array}$ & $\begin{array}{c}20,422 \\
(15,717-21,901)\end{array}$ & $\begin{array}{c}19,502 \\
(6,716-27,856)\end{array}$ & 0.81 \\
\hline Amount of contrast $(\mathrm{ml})$ & $360(265-435)$ & $405(280-585)$ & 0.24 \\
\hline $\begin{array}{l}\text { Total length of stents } \\
(\mathrm{mm})\end{array}$ & $81(56-111)$ & $119(84-142)$ & 0.11 \\
\hline
\end{tabular}

Interventional techniques applied, n (\%)

Retrograde techniques

\begin{tabular}{|l|c|c|c|}
\hline Reverse CART & $1(11)$ & $31(50)$ & 0.07 \\
\hline $\begin{array}{l}\text { Retrograde wire } \\
\text { crossing }\end{array}$ & $4(44)$ & $20(32)$ & 0.73 \\
\hline $\begin{array}{l}\text { Kissing wire technique } \\
\begin{array}{l}\text { Antegrade success } \\
\text { after retrograde failure }\end{array}\end{array}$ & $3(33)$ & $5(8)$ & 0.06 \\
\hline Failure & $1(11)$ & $5(10)$ & 1.00 \\
\hline Rendezvous technique & $2(22)$ & $0(0)$ & 0.57 \\
\hline Ping-pong technique & $3(33)$ & $0(0)$ & 0.02 \\
\hline Snaring & $2(22)$ & $3(5)$ & 0.12 \\
\hline
\end{tabular}

Devices applied, $\mathbf{n}(\%)$

Collateral wires

\begin{tabular}{l|c|c|c|}
\hline SION & $8(89)$ & $56(90)$ & 0.89 \\
\hline SION black & $0(0)$ & $3(5)$ & 1.00 \\
\hline Fielder FC & $0(0)$ & $3(5)$ & 1.00 \\
\hline Fielder XT-R & $1(11)$ & $0(0)$ & 0.13 \\
\hline \begin{tabular}{l} 
Microcatheters \\
\hline Corsair \\
\hline FineCross/SuperCross
\end{tabular} 5(59) & $58(94)$ & 0.61 \\
\hline NHancer & $2(22)$ & $2(52)$ & 0.76 \\
\hline Tornus & $0(0)$ & $2(3)$ & 0.08 \\
\hline Dual lumen MC & $3(33)$ & $4(7)$ & 0.04 \\
\hline
\end{tabular}

Antegrade guiding catheter sizes

\begin{tabular}{|c|c|c|c|}
\hline $6 \mathrm{Fr}$ & $1(11)$ & $18(19)$ & 0.43 \\
\hline $7 \mathrm{Fr}$ & $5(56)$ & $43(69)$ & 0.46 \\
\hline $8 \mathrm{Fr}$ & $3(33)$ & $1(2)$ & 0.01 \\
\hline Support catheter & $3(33)$ & $22(36)$ & 0.90 \\
\hline
\end{tabular}

cGy: centigray; SEM: standard error of mean 
from the LCA in $92 \%$ of cases. The most common right-sided ipsilateral CCs revealed an epimyocardial course in $81 \%$ of the patients, and a septal intramyocardial course in $19 \%$ of the patients.

The most common type of ipsilateral epimyocardial CCs were of type A, B and D (Figure 1). They can originate from a high marginal branch inserting to the right posterolateral artery (RPLA) or from a lower marginal branch to the posterior descending artery (PDA) (Figure 1A). Sometimes, ipsilateral CCs can simply connect the distal ends of a higher and a lower right marginal branch, thereby bridging the CTO (Figure 1B). Epimyocardial ipsilateral CCs can also directly originate from the proximal part of the RCA and insert close to the crux cordis (Figure 1C), or they may reveal a longer epimyocardial course finally inserting at the distal part of the RPLA (Figure 1D). In particular, ipsilateral intramyocardial septal CCs have rarely been described. This intramyocardial artery is also called the right superior descending artery (Figure 1E).

Epimyocardial CCs are thinner (Werner class, CC class $0-1)^{8}$, more fragile/vulnerable and prone to rupture. In contrast, intramyocardial septal CCs reveal a straightforward, shorter and more stable course, originating from either the proximal or distal part of the RCA (CC type 0 or type 1$)^{8}$.

After reviewing a total of 47 angiograms with ipsilateral CCs of the RCA, ipsilateral CCs of types A, D and E appeared to be technically feasible to attempt the ipsilateral retrograde approach (Figure 1). Retrospectively, type C ipsilateral CCs were assessed as

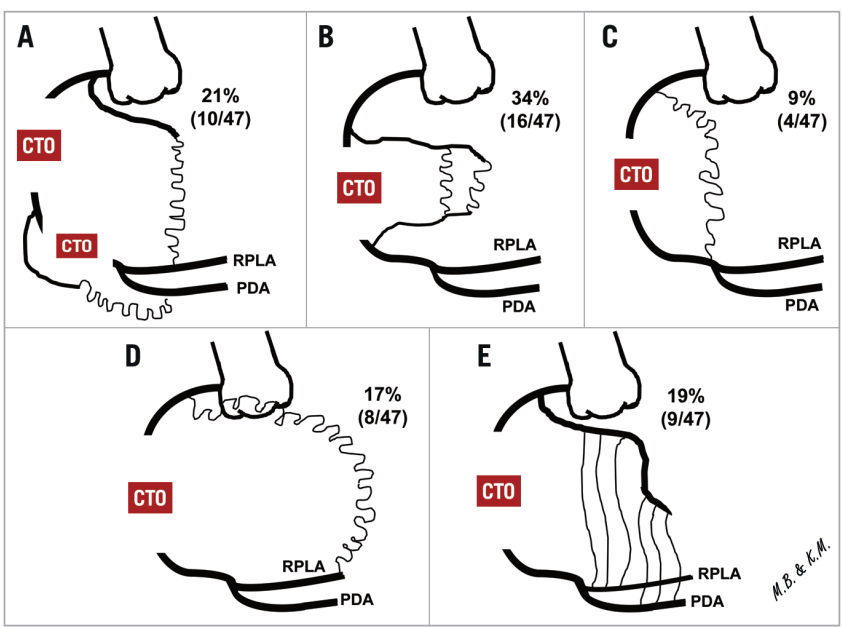

Figure 1. The varying courses and frequency of ipsilateral CCs of the $R C A$. A) Type A: CCs originating from a high marginal branch (RM) inserting to the right posterolateral artery (RPLA) or from a lower $R M$ to the posterior descending artery (PDA). B) Type B: CCs linking distal ends of higher and lower RMs, thereby bridging the $C T O$ of the RCA. C) Type C: CCs originating directly from the proximal RCA and inserting close to the crux cordis. D) Type D: CCs with a longer epimyocardial course inserting at the distal part of the RPLA. E) Type E: septal intramyocardial, ipsilateral CCs, also called right superior descending artery. (Curved lines correspond to an epimyocardial course, straight lines correspond to an intramyocardial course of CCs). potentially passable. In contrast, ipsilateral CCs of type B seemed to be less suited for a safe retrograde percutaneous approach, because they are characterised by a very tortuous and fragile epimyocardial course with a high risk of vessel damage (Figure 2$)^{9}$.

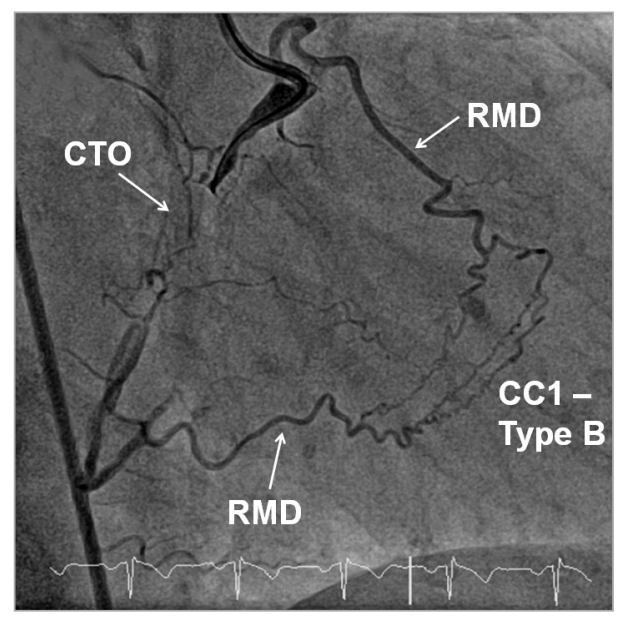

Figure 2. Epimyocardial CCs of type B of the RCA (Werner class 1) linking distal ends of higher and lower RM branches and revealing a very tortuous and fragile epimyocardial course not recommended to be used for the ipsilateral retrograde approach.

\section{GENERAL ASPECTS FOR THE RETROGRADE IPSILATERAL APPROACH}

Ipsilateral CCs can often be visualised during coronary angiography, usually achieved by simultaneous dual injection into the RCA and $\mathrm{LCA}^{8}$. Often, ipsilateral $\mathrm{CCs}$ originate at the very proximal part of the RCA or they may originate separately above the RCA ostium within a single ostium. Accordingly, ipsilateral CCs might easily be overlooked due to a deep intubation of the RCA ostium by the guiding catheter. A simultaneous injection into the separate ostia of both the ipsilateral CC and the RCA might additionally reveal helpful information (Figure 3).

\section{EPIMYOCARDIAL CCS OF TYPE A, C AND D FOR THE RETROGRADE IPSILATERAL APPROACH}

Based on our experience, epimyocardial CCs of type A, C and $\mathrm{D}$ can be passed without increasing the risk of vessel damage by new-generation guidewires, such as the SION (blue or black) and Fielder XT-R (both ASAHI Intecc, Aichi, Japan) in combination with microcatheters (MC). Frequently, a weak back-up of the guiding catheter might become evident while passing epimyocardial CCs. In these situations, the additional insertion of a GuideLiner ${ }^{\circledR}$ catheter (Vascular Solutions, Minneapolis, MN, USA) strengthens back-up (Figure 3).

Specifically for epimyocardial CCs of type A, the use of MCs such as the Corsair (ASAHI Intecc) or the FineCross ${ }^{\circledR}$ MG (Terumo Medical Corporation, Somerset, NJ, USA) can be recommended. In even smaller epimyocardial CCs as well as after failed 


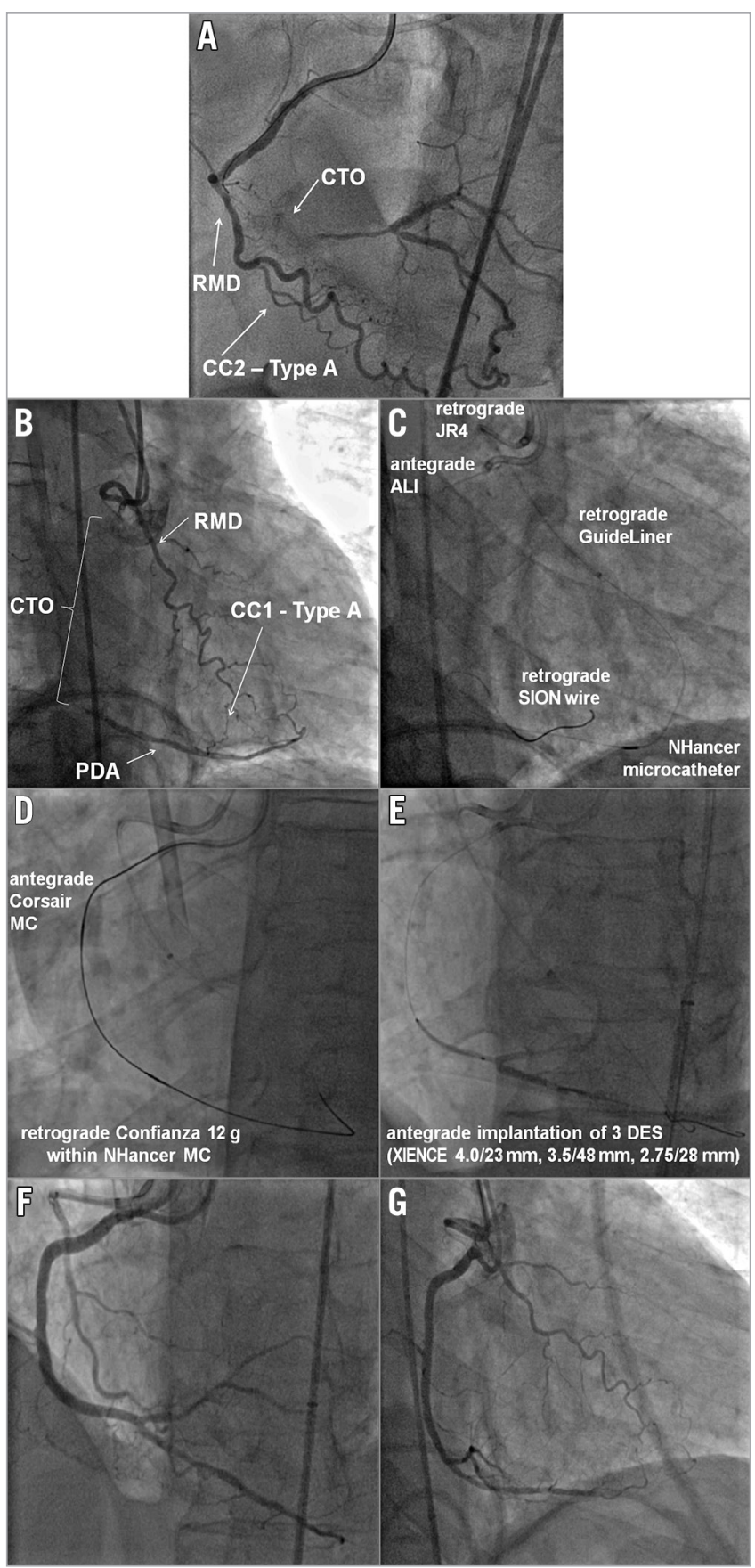

Figure 3. Successful retrograde approach using ipsilateral epimyocardial CCs of type A. A) Epimyocardial CCs of type A of the $R C A$ (Werner class 2) originating from a low right marginal branch (RMD) and bridging the RCA-CTO. B) Type A CCs (Werner class 1) bridging a long CTO of the RCA. Type A CCs originate from a high marginal branch (RMD) and insert in the $P D A . C)$ The retrograde JR 4.0 guiding catheter with a GuideLiner intubating the separate ostium of the high RMD. $A$ retrograde SION wire is advanced within the NHancer $M C$.

D) The exchanged retrograde Confianza $12 \mathrm{~g}$ wire being inserted into the antegrade Corsair MC in a "rendezvous" technique. E) Antegrade implantation of three DES (XIENCE PRO 4.0/23, $3.5 / 48,2.75 / 28 \mathrm{~mm}$ ), while $F$ ) \& $G$ ) show the final result after successful revascularisation. attempts using the Corsair MC, alternative use of the NHancer (IMDS, Roden, The Netherlands) may allow further progress (Figure 3). The NHancer is thinner and more flexible, whereas it provides weaker back-up compared to the Corsair MC.

Notably, one of the main responsibilities of the operator is to avoid the development of increasing shear stress during wire externalisation within thin epimyocardial vessels. Significant shear stress can increase the risk of fatal collateral damage and might permanently destroy epimyocardial CCs. We recommend using the "rendezvous" technique ${ }^{10}$ in order to reduce potential shear stress in these scenarios (Figure 4). In general, the "rendezvous" technique can be performed within the antegrade guiding catheter after a reverse controlled antegrade and retrograde subintimal tracking (CART) manoeuvre ${ }^{11,12}$.

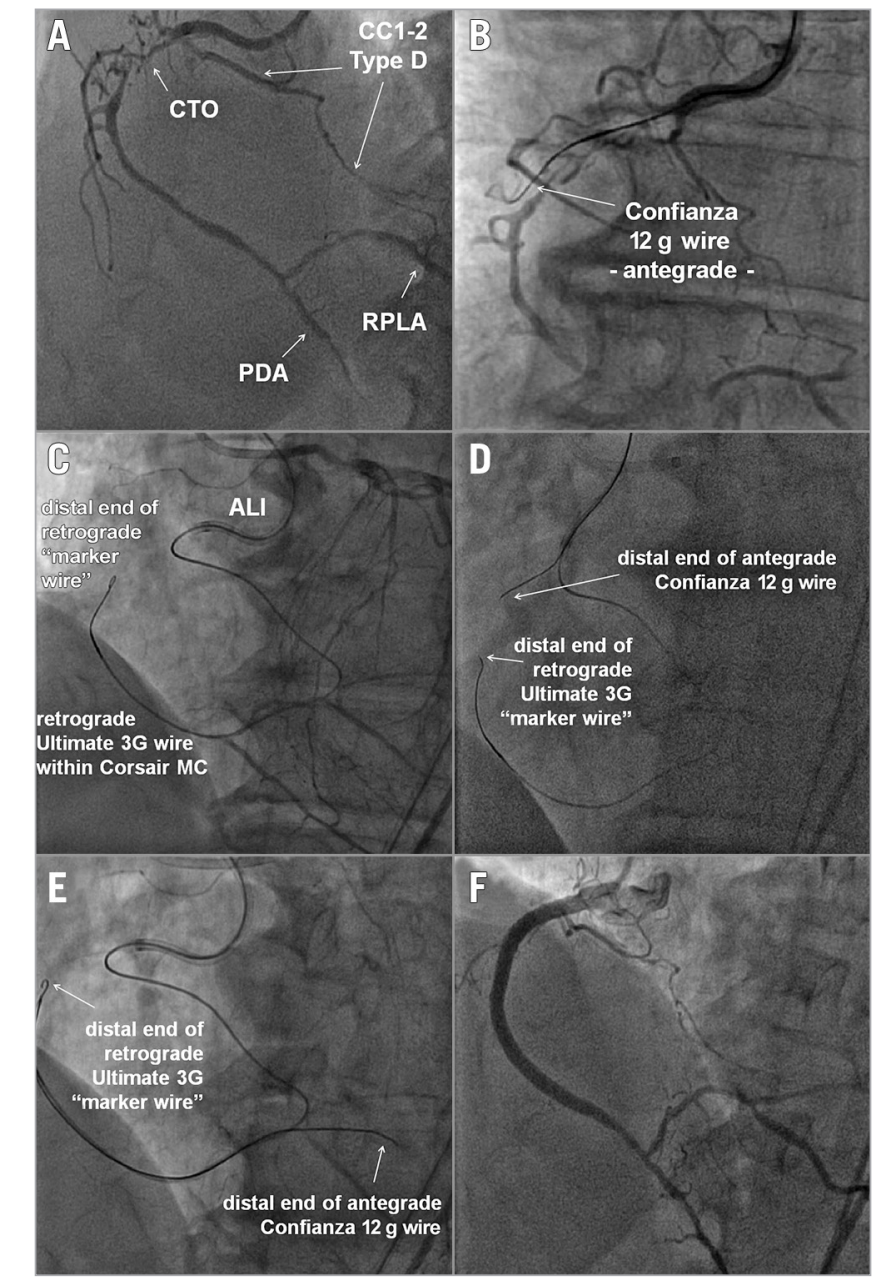

Figure 4. Retrograde approach using ipsilateral epimyocardial CCS of type D (Werner class 1-2). A) Inserting at the distal RPLA. B) An antegrade subintimal Confianza $12 \mathrm{~g}$ wire. C), D) and E) Successful retrograde advancement of a retrograde Ultimate $3 G$ wire within a Corsair MC serving as a retrograde "marker wire". An antegrade Confianza $12 \mathrm{~g}$ wire was advanced towards the retrograde "marker wire" and finally passes the CTO of the RCA.F) The final result after PCI. 


\section{INTRAMYOCARDIAL CCS OF TYPE E FOR THE RETROGRADE IPSILATERAL APPROACH}

Intramyocardial septal CCs (i.e., right superior descending artery) usually depart with a steeper angle of up to $90^{\circ}$ from the RCA (Figure 5, Figure 6). Optimal coaxial alignment of the guiding catheter is necessary to reach optimal entry into septal CCs. The most appropriate guiding catheter is a JR 4.0 with a diameter of $7 \mathrm{Fr}$, ensuring an increased back-up without deep intubation. Based on our experience, to pass ipsilateral intramyocardial septal CCs compared to contralateral intramyocardial septal CCs appears to be technically more feasible, because the latter are characterised by an even longer and more tortuous course.

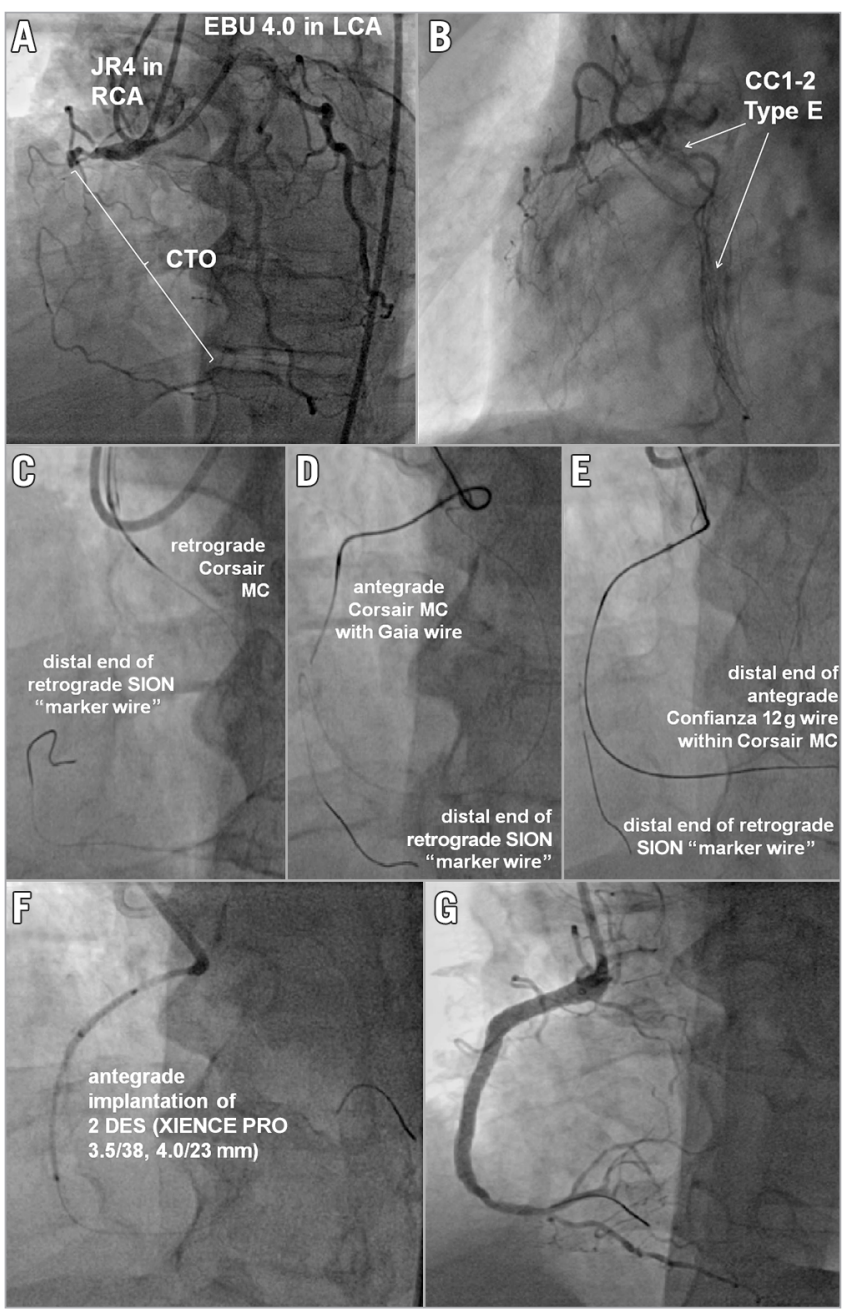

Figure 5. Retrograde ipsilateral approach using CCs of type E . A) \& B) Retrograde approach using ipsilateral intramyocardial, septal CCs of type E (Werner class 1-2). C), D) \& E) Successful retrograde advancement of a retrograde SION wire within a Corsair $M C$ serving as a retrograde "marker wire". An antegrade Gaia wire was advanced towards the retrograde "marker wire" within an antegrade Corsair MC. Finally a Confianza $12 \mathrm{~g}$ wire punctured the distal cap. F) and $G$ ) Final result after PCI with implantation of two DES (XIENCE PRO 3.5/38; 4.0/23 mm; Abbott Vascular, Santa Clara, CA, USA).

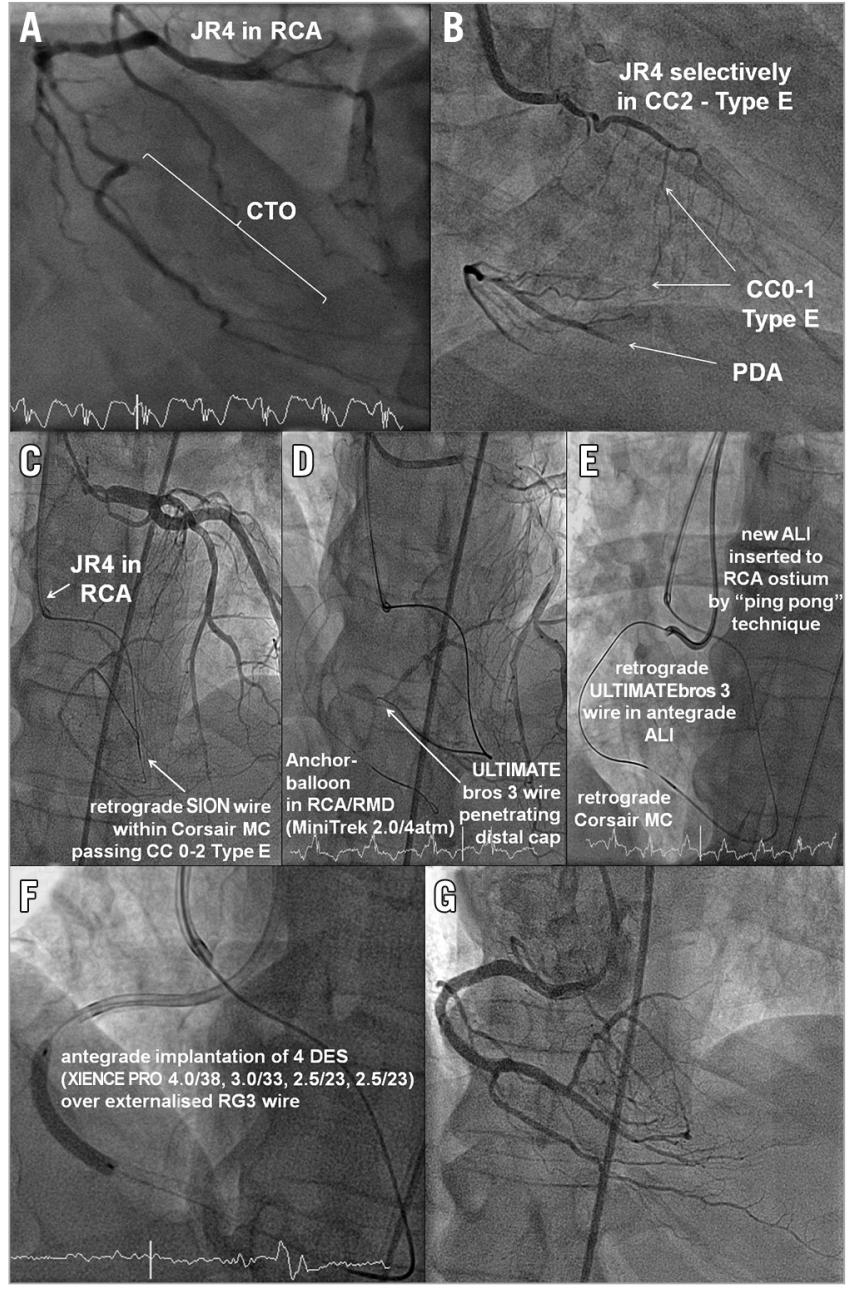

Figure 6. Retrograde approach using ipsilateral intramyocardial, septal CCs of type E (Werner class 1-2). A) CTO of the distal RCA. $B$ ) Selective intubation of the separate ostium of the intramyocardial, septal CC with departing CCs of Werner class 0-1. C) Successful retrograde advancement of a retrograde SION wire within a Corsair MC. D) Antegrade anchor-balloon technique (MINI TREK 2.0 [Abbott Vascular], 4 atm) in the RMD guaranteeing increasing back-up. An ULTIMATEbros 3 wire (ASAHI Intecc) penetrates the distal cap of the CTO (D) and is finally advanced into the retrograde ALI guiding catheter, being inserted at the RCA ostium by the "ping-pong" technique (E). F) and G) Final result after PCI with implantation of four DES (XIENCE PRO 4.0/38, 3.0/33, 2.5/23, 2.5/23).

After successful passage of septal CCs, the intraluminal MC and wire localisation within either the PDA or the RPLA has to be confirmed by contralateral injection from the LCA (Figure $\mathbf{5}$, Figure 6). The use of a second guiding catheter placed into the RCA ostium according to the "ping-pong" technique optimises the technical feasibility of reverse CART (Figure 6) ${ }^{7}$. After successful reverse CART, a long externalisation wire (e.g., RG3 wire; ASAHI Intecc) should be inserted around the revascularised pathway ${ }^{2}$. The retrograde approach will be completed with final antegrade percutaneous implantation of appropriately sized coronary stents (Figure 6). 


\section{Discussion}

The present analysis systematically describes an alternative retrograde approach to treat CTOs of the RCA percutaneously, using ipsilateral CCs in order to expand the spectrum of interventional techniques of percutaneous treatment of CTOs of the RCA.

Of note, ipsilateral CCs of the RCA can be found far more often than supposed; however, they have to be visualised on purpose during elaborate coronary angiography. The most common types of epimyocardial ipsilateral CCs of the RCA can be classified into the four types A-D, followed by intramyocardial mostly septal CCs (type E) - also called right superior descending arteries - most often being characterised by Werner classification 0 or $1^{8}$.

The percutaneous treatment of CTOs using ipsilateral CCs is technically challenging; however, it is feasible and should be reserved for experienced retrograde CTO operators.

Except for type B ipsilateral CCs, all other types of ipsilateral CCs (type A, C, D, E) can be attempted for the retrograde approach. The most important risk factor of this strategy consists of increased shear stress within epimyocardial CCs during wire externalisation, which can be minimised by the "rendezvous" technique. Additional use of the so-called "ping-pong" technique is helpful in situations with an ostial or proximal departure of a high marginal branch of the RCA, as previously described by Brilakis et $\mathrm{al}^{7}$. In the presence of CCs with a high degree of tortuosity, alternative interventional techniques such as "septal surfing"13 using invisible contralateral LAD septal CCs may provide a more promising and faster route.

The retrograde approach presented, using ipsilateral CCs, might provide an alternative treatment option in the following clinical situations: (1) patients with $\mathrm{CABG}$ and a concomitant occluded LAD; (2) patients with diffuse and relevant coronary artery stenoses of the left main trunk (LMT); (3) patients with a functional, "last vessel situation" of the LCA; (4) after a failed antegrade or retrograde attempt using contralateral CCs; (5) in the presence of inappropriate contralateral CCs.

\section{Impact on daily practice}

The percutaneous treatment of chronic total occlusions of the RCA using the retrograde ipsilateral approach might be a feasible option in specific anatomic morphologies. However, we recommend avoiding conventional wire externalisation after passing thin ipsilateral epimyocardial CCs in order to reduce shear stress and potential rupture of the epimyocardial CCs. The percutaneous treatment of CTOs using ipsilateral CCs is technically challenging and should be reserved for experienced retrograde CTO operators.

\section{Conflict of interest statement}

The authors have no conflicts of interest to declare.

\section{References}

1. Sianos G, Werner GS, Galassi AR, Papafaklis MI, Escaned J, Hildick-Smith D, Christiansen EH, Gershlick A, Carlino M, Karlas A, Konstantinidis NV, Tomasello SD, Di Mario C, Reifart N; Euro CTO Club. Recanalisation of chronic total coronary occlusions: 2012 consensus document from the EuroCTO club. EuroIntervention. 2012;8:139-45.

2. Brilakis ES, Grantham JA, Rinfret S, Wyman RM, Burke MN, Karmpaliotis D, Lembo N, Pershad A, Kandzari DE, Buller CE, DeMartini T, Lombardi WL, Thompson CA. A percutaneous treatment algorithm for crossing coronary chronic total occlusions. JACC Cardiovasc Interv. 2012;5:367-79.

3. Di Mario C, Barlis P, Tanigawa J, Locca D, BucciarelliDucci C, Kaplan S, Katoh O. Retrograde approach to coronary chronic total occlusions: preliminary single European centre experience. EuroIntervention. 2007;3:181-7.

4. EuroCTO Club. European Registry on Chronic Total Occlusions (ERCTO); http://www.ercto.org/. http://www.ercto.org/.

5. Chandra S, Vijay SK, Dwivedi SK. Successful recanalization of a left anterior descending chronic total occlusion via an ipsilateral intraseptal collateral using reverse CART technique. J Invasive Cardiol. 2013;25:E72-4.

6. Suzuki M, Takagi Y, Tsuchikane E. Percutaneous coronary intervention of chronic total occlusion in a left anterior descending coronary artery using an ipsilateral intraseptal bridging collateral tracking technique. Catheter Cardiovasc Interv. 2010;76:536-40.

7. Brilakis ES, Grantham JA, Banerjee S. "Ping-pong" guide catheter technique for retrograde intervention of a chronic total occlusion through an ipsilateral collateral. Catheter Cardiovasc Interv. 2011;78:395-9.

8. Werner GS, Ferrari M, Heinke S, Kuethe F, Surber R, RichartzBM, Figulla HR. Angiographic assessment of collateral connections in comparison with invasively determined collateral function in chronic coronary occlusions. Circulation. 2003;107:1972-7.

9. Rathore S, Katoh O, Matsuo H, Terashima M, Tanaka N, Kinoshita Y, Kimura M, Tsuchikane E, Nasu K, Ehara M, Asakura K, Asakura Y, Suzuki T. Retrograde percutaneous recanalization of chronic total occlusion of the coronary arteries: procedural outcomes and predictors of success in contemporary practice. Circ Cardiovasc Interv. 2009;2:124-32.

10. Kim MH, Yu LH, Mitsudo K. A new retrograde wiring technique for chronic total occlusion. Catheter Cardiovasc Interv. 2010;75:117-9.

11. Niccoli G, Ochiai M, Mazzari MA. A complex case of right coronary artery chronic total occlusion treated by a successful multi-step Japanese approach. J Invasive Cardiol. 2006;18:E230-3.

12. Joyal D, Afilalo J, Rinfret S. Effectiveness of recanalization of chronic total occlusions: a systematic review and meta-analysis. Am Heart J. 2010;160:179-87.

13. Sianos G, Karlas A. Tools \& Techniques: CTO--the retrograde approach. EuroIntervention. 2011;7:285-7. 